The Commissioning of Electrical Plant and Associated Problems

By R. C. H. Richardson. (Monographs on Electrical Engineering, Vol. 5.) Pp. xvi+363. (London : Chapman and Hall, Ltd., 1938.) 21s. net.

$\mathrm{E}$ VGINEERS on the whole do not exhibit reticence when recounting difficulties they may have experienced during the commissioning of electrical machinery and plant; but when it comes to publishing such an account, even if time and circumstances permit, the greater the diversity and interest of these experiences the less are they likely to appear in print. It is not surprising that this dearth of literature leads to expectations being aroused, perhaps unduly, if at last what appears to be a record of personal experiences is published.

The book under review gives rise to a reaction which is one of disappointment, for it is distinctly lacking both as regards personal appeal and the recording of instances of the surmounting of 'teething troubles'. In the first place, someone ought to have persuaded the author to discard elementary theory, such as the derivation of the equivalent circuit of a transformer or the elementary theory of vectors, which is to be found in so many existing text-books, and utilize the space thus gained for more meaty matter. Not a few cases of trouble from 'noise' have been encountered when commissioning transformers; yet, in this book, noise does not figure in the index or in the text. The vibration and noise of machinery, it is true, are mentioned on p. 84, but methods of measurement, treatment or cure are not described.

Mathematical treatment has been avoided, but at a price, for instead of being an advanced treatise the book is largely descriptive though lacking photographic illustrations. The text is supported by numerous line diagrams and there is a short bibliography, but it is considered that the list of books given is totally inadequate. Such a serious trouble as that of 'hunting' is not dealt with in the section on alternators and is not referred to in the bibliography.

In favour of the book it may be said that it would serve to guide a reader to the many matters which he may have to study deeply if he is to have confidence in commissioning machinery and plant.

\section{Psychology, Psychotherapy and Evangelicalism}

By Prof. J. G. McKenzie. Pp. xiii +238. (London : George Allen and Unwin, Ltd., 1940.) 10s. 6d. net.

$\mathrm{P}^{\mathrm{s}}$

YCHO-THERAPEUTIC techniques provide new means for a study of the various types of religious experience, and Prof. McKenzie applies them to the study of Evangelicalism. For examining it he has the important qualification of having shared in the evangelical experience himself. Evangelical Christianity has suffered much from the dramatizing tendencies of its exponents ; they have laboured to heighten the vividness of the colour scheme, and the result has been that they have presented the world with something fantastic. The actual facts are more sober. Not all evangelicals are of the 'twice-born' type, nor does the root and centre of their religious experience invariably lie in mystical states of consciousness. Anxious to induce in their converts a conviction of sin, evangelical teachers have sought to deepen their sense of guilt. Prof. McKenzie writes at length and with great insight upon this point, making a clear distinction between "the true sense of $\sin$ which involves repentance, and the sense of guilt which is always the outcome of repression and must be removed before repentance and forgiveness can take place". He holds that the well-meant attempt to deepen the sense of guilt "not only does damage to the personality but is a hindrance to evangelical Christianity".

In a most interesting section on "The Meaning of Sin", Prof. McKenzie makes a distinction between "two absolutely different types of personality": the "Ego-centred" and the "Object-centred". The former "makes himself his own main purpose", consciously or unconsciously. The popular notion that virtue consists in "the integration of the personality" is not accepted by the author, for "This integration is not a moral process in itself". The quality of the integrated self depends "on what moral principle has integrated it". Prof. McKenzie has a most illuminating section upon forgiveness; and indeed his book as a whole is so full of valuable material that it will repay study not only by psychologists but also by theologians and ministers of religion. J. C. H.

\section{A Pocket Medical Dictionary}

Compiled by Lois Oakes, assisted by Thos. B. Davie. Fourth edition. Pp. $x x+409$. (Edinburgh : E. and S. Livingstone, 1940.) 3s. $6 d$. net.

1 $\mathrm{HE}$ distinctive features of this popular little book, the modest price of which makes it specially suitable for medical students and nurses, are the addition of many new words and the deletion of those no longer current, an appendix on first aid, and an anatomical chart of the human body. We have noticed only one serious mistake, namely, "rotheln" (without an umlaut) stated to be the same as "measles", while the following words should be inserted in the next edition: "barbiturates", "erysipeloid", "erythema infectiosum", "fourth" disease" and "tularæmia".

Diathermie chirurgicale

Par Dr. C. A. Arraud. (Les actualités physiothérapiques, 1 : Ellectrothérapie, 7). Pp. iv +216. (Paris : Gauthier-Villars, 1939.) 50 francs.

7 HIS clear and concise little work by Dr. C. A. Arraud, assistant in physiotherapy at the Hôtel Dieu, Paris, is divided into two main parts. In the first, which is introductory, the author deals with the historical aspects of surgical diathermy, the various currents employed, and the choice of an apparatus, particularly those of French origin. The second part is concerned with the employment of surgical diathermy in cancer and in disorders of various systems, such as diseases of the skin, gynæcology, urology, diseases of the alimentary system, neurology, respiratory diseases, otorhinolaryngology and ophthalmology. 